\title{
Closely related phytoplankton species produce similar suites of dissolved organic matter
}

\author{
Jamie W. Becker ${ }^{1,2}$, Paul M. Berube ${ }^{2}$, Christopher L. Follett ${ }^{3}$, John B. Waterbury ${ }^{1}$, \\ Sallie W. Chisholm ${ }^{2,4}$, Edward F. DeLong ${ }^{2,5}$ and Daniel J. Repeta ${ }^{3 *}$ \\ ${ }^{1}$ Department of Biology, Woods Hole Oceanographic Institution, Woods Hole, MA, USA \\ 2 Department of Civil and Environmental Engineering, Massachusetts Institute of Technology, Cambridge, MA, USA \\ ${ }^{3}$ Department of Marine Chemistry and Geochemistry, Woods Hole Oceanographic Institution, Woods Hole, MA, USA \\ ${ }^{4}$ Department of Biology, Massachusetts Institute of Technology, Cambridge, MA, USA \\ ${ }^{5}$ Department of Biological Engineering, Massachusetts Institute of Technology, Cambridge, MA, USA
}

\section{Edited by:}

Jennifer Pett-Ridge, Lawrence

Livermore National Lab, USA

\section{Reviewed by:}

Tom Metz, Pacific Northwest National Laboratory, USA

Xavier Mayali, Lawrence Livermore

National Laboratory, USA

*Correspondence:

Daniel J. Repeta, Department of

Marine Chemistry and

Geochemistry, Woods Hole

Oceanographic Institution, Watson

Building, MS \#51, 266 Woods Hole

Rd., Woods Hole, MA 02543, USA

e-mail:drepeta@whoi.edu
Production of dissolved organic matter (DOM) by marine phytoplankton supplies the majority of organic substrate consumed by heterotrophic bacterioplankton in the sea. This production and subsequent consumption converts a vast quantity of carbon, nitrogen, and phosphorus between organic and inorganic forms, directly impacting global cycles of these biologically important elements. Details regarding the chemical composition of DOM produced by marine phytoplankton are sparse, and while often assumed, it is not currently known if phylogenetically distinct groups of marine phytoplankton release characteristic suites of DOM. To investigate the relationship between specific phytoplankton groups and the DOM they release, hydrophobic phytoplankton-derived dissolved organic matter (DOMP) from eight axenic strains was analyzed using high-performance liquid chromatography coupled to mass spectrometry (HPLC-MS). Identification of DOM features derived from Prochlorococcus, Synechococcus, Thalassiosira, and Phaeodactylum revealed DOMP to be complex and highly strain dependent. Connections between DOMP features and the phylogenetic relatedness of these strains were identified on multiple levels of phylogenetic distance, suggesting that marine phytoplankton produce DOM that in part reflects its phylogenetic origin. Chemical information regarding the size and polarity ranges of features from defined biological sources was also obtained. Our findings reveal DOMp composition to be partially conserved among related phytoplankton species, and implicate marine DOM as a potential factor influencing microbial diversity in the sea by acting as a link between autotrophic and heterotrophic microbial community structures.

Keywords: dissolved organic matter, untargeted metabolomics, marine phytoplankton, exometabolome, Prochlorococcus, Synechococcus, Thalassiosira, Phaeodactylum

\section{INTRODUCTION}

Extracellular release of dissolved organic matter (DOM) by marine phytoplankton fuels secondary production in the sea (Pomeroy, 1974; Mague et al., 1980; Fogg, 1983; Baines and Pace, 1991). As much as $50 \%$ of the total carbon fixed by photoautotrophs may be released into seawater as a by-product of normal metabolism, or through active processes for waste removal, substrate acquisition, defense, or communication (Bjornsen, 1988; Carlson, 2002; Bertilsson and Jones, 2003). The amount of extracellular DOM released and its composition depend on the organism and its physiological state (Myklestad, 1995; Meon and Kirchman, 2001; Wetz and Wheeler, 2007; Romera-Castillo et al., 2010), as well as additional factors including: temperature, light, growth phase, availability of inorganic nutrients, and the presence of other organisms (Hirt et al., 1971; Obernosterer and Herndl, 1995; Grossart and Simon, 2007; Barofsky et al., 2009; Engel et al., 2011). Factors affecting DOM uptake are less clear, but recent evidence suggests that DOM resource partitioning within microbial communities may impact the ecological success and community structure of heterotrophic bacterioplankton
(McCarren et al., 2010; Poretsky et al., 2010; Nelson and Carlson, 2012; Sarmento and Gasol, 2012). Substrate specificity may be of particular importance for heterotrophs that have evolved streamlined genomes and are therefore fine-tuned to particular resources (Giovannoni et al., 2005, 2008).

Genomic and physiological differences among marine phytoplankton likely influence the nature of the organic matter they produce, and consequently, what substrates are available to sympatric heterotrophic communities. If different phytoplankton groups release DOM of varying composition and lability, then DOM could provide a direct link between autotrophic and heterotrophic microbial diversity and community structure. For example, Prochlorococcus is frequently the numerically dominant photoautotroph in oligotrophic surface waters and is an essential source of organic matter used by heterotrophic bacterioplankton in this environment (Partensky et al., 1999; Bertilsson et al., 2005; Flombaum et al., 2013). It has been suggested that DOM released by Prochlorococcus could be responsible for supporting $12-41 \%$ of bacterial production in tropical and subtropical regions (Bertilsson et al., 2005). If DOM released by Prochlorococcus 
is distinct in composition, metabolic specialization to utilize Prochlorococcus-derived DOM within associated heterotrophic populations may influence bacterioplankton community structure in these regions.

Several recent studies have employed phytoplankton-derived DOM for use in the study of microbial DOM consumption (Romera-Castillo et al., 2011; Nelson and Carlson, 2012; Sarmento and Gasol, 2012; Landa et al., 2013a,b; Sharma et al., 2013), with the implied assumption that DOM suites derived from individual phytoplankton strains represent compositionally distinct organic substrates. However, a comparative assessment of phytoplankton-derived DOM has not been conducted at the molecular level and it is not yet clear how much chemical variation exists in DOM produced by different marine phytoplankton types. Furthermore, it is not known how DOM composition varies as a function of taxonomic or phylogenetic relatedness among different phytoplankton species. Investigating how DOM produced by marine phytoplankton varies with phylogenetic relatedness may help us to better understand marine microbial community structure, allow us to target important components of DOM in future studies, and potentially improve our predictive powers regarding the composition of DOM produced by different phytoplankton communities.

To investigate the relationship between phylogenetic relatedness and DOM composition, we used HPLC-MS to detect chemical features in DOM released by laboratory cultures of marine phytoplankton. While the determination of empirical formulae within DOM is now possible through advances in ultrahighresolution mass spectrometry, definitive chemical identifications in untargeted metabolomic footprinting studies remain a challenge due to structural complexities including isomerization and the magnitude of unknown metabolites that comprise both marine (Nebbioso and Piccolo, 2013) and phytoplankton-derived DOM (Schwarz et al., 2013). Rather than attempt chemical identifications with no a priori knowledge regarding compounds of interest, we chose to sacrifice mass resolution for chromatographic separation, providing us with two independent parameters (i.e., polarity and mass) to detect and compare chemical features in DOM released by eight marine phytoplankton strains. These strains were selected to encompass both the Bacteria and Eukarya domains. Cyanobacterial strains within the genera Prochlorococcus and Synechococcus were chosen to represent cells with different adaptations to light and temperature. Thalassiosira and Phaeodactylum were chosen to represent different groups of eukaryotic diatoms (centric and pennate, respectively). Selection of these strains provided both broad phylogenetic coverage as well as examples of closely related organisms with unique physiologies. Hundreds to thousands of features detected in each culture sample were used to chemically compare DOM produced by phytoplankton strains with differing degrees of relatedness. The suite of features associated with each strain was then compared with phylogenies deduced from both rRNA and whole genome comparisons to uncover novel connections between phytoplankton phylogeny and DOM composition.

\section{MATERIALS AND METHODS PHYTOPLANKTON CULTURES}

Eight species of marine phytoplankton were selected for this study to investigate variability in the composition of organic matter released by unicellular photoautotrophs at various taxonomic levels (Table 1). Individual strains were chosen on the criteria that a published sequenced genome is, or will soon be available, and that axenic strains were capable of growth to high cell densities (ca. $10^{7}$ cells $/ \mathrm{ml}$ ) in natural seawater-based media. All media was

Table 1 | DOMP features detected using HPLC-ESI-MS after blank subtraction.

\begin{tabular}{|c|c|c|c|c|c|c|c|c|}
\hline \multirow[t]{2}{*}{ Phytoplankton } & \multicolumn{3}{|c|}{ Features } & \multicolumn{3}{|c|}{ Unique features } & \multirow[t]{2}{*}{ Common features } & \multirow[t]{2}{*}{ Total features } \\
\hline & Replicate A & Replicate B & Replicate C & Replicate A & Replicate B & Replicate C & & \\
\hline Prochlorococcus ${ }^{a}$ & & & & & & & 43 & 328 \\
\hline MIT9313 & 321 & 303 & 307 & 97 & 128 & 121 & 123 & 577 \\
\hline MIT9301 & 449 & 430 & 459 & 72 & 130 & 38 & 232 & 673 \\
\hline MED4 & NA & 346 & 247 & NA & 216 & 117 & 130 & 463 \\
\hline Synechococcus ${ }^{\mathrm{b}}$ & & & & & & & 68 & 483 \\
\hline WH8102 & 642 & 586 & 516 & 76 & 57 & 58 & 389 & 773 \\
\hline WH7803 & 299 & 324 & 255 & 47 & 44 & 61 & 162 & 434 \\
\hline Diatoms $^{c}$ & & & & & & & 31 & 1478 \\
\hline CCMP632 & 876 & 918 & 1026 & 60 & 42 & 151 & 693 & 1190 \\
\hline CCMP1647 & 696 & 956 & 543 & 44 & 288 & 38 & 435 & 1065 \\
\hline CCMP1335 & 832 & 757 & 659 & 139 & 56 & 44 & 541 & 973 \\
\hline
\end{tabular}

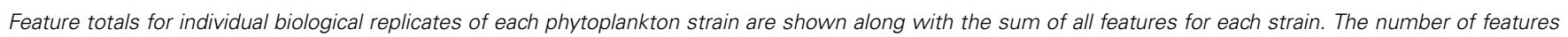

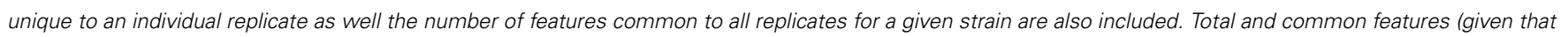
each feature was shared among biological replicates) are provided for each organism group.

a Described in Moore and Chisholm (1995); Moore et al. (1998); Rubio et al. (1999); Rocap et al. (2002, 2003).

${ }^{b}$ Described in Waterbury et al. (1986); Rocap et al. (2002); Palenik et al. (2003).

c Described in Sorhannus (2004); De Martino et al. (2007); Alverson et al. (2011). 
prepared by the National Center for Marine Algae and Microbiota (NCMA) using filtered, autoclaved surface water collected from the Sargasso Sea. Media amendments were added aseptically after sterilization. Triplicate $1 \mathrm{~L}$ batch cultures of each strain were prepared alongside triplicate $1 \mathrm{~L}$ controls containing all media amendments, but no cell additions. Cells were pre-conditioned in 60-400 $\mathrm{ml}$ of the appropriate medium prior to inoculation in $1 \mathrm{~L}$.

Thalassiosira pseudonana (CCMP str. 1335), Thalassiosira rotula (CCMP str. 1647), Phaeodactylum tricornutum (CCMP str. 632), and both Synechococcus strains (WH8102 and WH7803) were grown at the NCMA in L1 medium prepared according to existing protocols (Guillard and Hargraves, 1993). Diatom strains were grown at $20^{\circ} \mathrm{C}$ and Synechococcus strains at $24^{\circ} \mathrm{C}$. All five strains were grown on a 13/11 light/dark cycle with gentle periodic mixing. Synechococcus str. WH7803 was grown under $10-20 \mu \mathrm{mol}$ photons $/ \mathrm{m}^{2} / \mathrm{s}$ illumination, while the remaining strains were grown at $100-120 \mu \mathrm{mol}$ photons $/ \mathrm{m}^{2} / \mathrm{s}$. Diatom cells were enumerated using a Palmer-Maloney counting chamber at 40X magnification on a Zeiss light microscope. Synechococcus cells were enumerated via epifluorescence microscopy. Three Prochlorococcus strains (MED4, MIT9301, and MIT9313) were grown at $22^{\circ} \mathrm{C}$ in Pro99 medium prepared by the NCMA according to existing protocols (Moore et al., 2002, 2007) with the addition of $5 \mathrm{mM}$ sodium bicarbonate. All three strains were grown on a 14/10 light/dark cycle. Prochlorococcus str. MIT9313 was grown under low light conditions at ca. $20 \mu \mathrm{mol}$ photons $/ \mathrm{m}^{2} / \mathrm{s}$, while MIT9301 and MED4 were grown at ca. $40 \mu \mathrm{mol}$ photons $/ \mathrm{m}^{2} / \mathrm{s}$. Prochlorococcus cultures were monitored for growth using total fluorescence and for changes in $\mathrm{pH}$, which were mitigated by additions of $2 \mathrm{mM}$ HEPES buffer and $5 \mathrm{mM}$ sodium bicarbonate 6 days after inoculation (sensu Moore et al., 2007). Samples for direct cell counts by flow cytometry were fixed with $0.125 \%$ final concentration of grade I glutaraldehyde (Sigma) and stored at $-80^{\circ} \mathrm{C}$ prior to analysis. Fixed samples were diluted in $0.2 \mu \mathrm{m}$ filtered seawater and Prochlorococcus were enumerated using an Influx Cell Sorter (BD Biosciences) as previously described (Olson et al., 1985; Cavender-Bares et al., 1999).

\section{ORGANIC MATTER PRODUCTION}

Samples for cell enumeration and particulate and dissolved organic carbon (POC and DOC, respectively) quantification were taken at the onset of stationary phase growth to evaluate organic carbon production by each strain. An exception was that DOC data for Prochlorococcus strains was not acquired due to the addition of HEPES buffer during growth to mitigate $\mathrm{pH}$ changes (sensu Moore et al., 2007). All organic carbon samples were processed using combusted $\left(450^{\circ} \mathrm{C}\right.$ for $\left.8 \mathrm{~h}\right)$ glassware. Duplicate samples for POC analysis were taken by vacuum filtering $25 \mathrm{ml}$ of sample onto a combusted $25 \mathrm{~mm} 0.7 \mu \mathrm{m}$ glass fiber filter (Whatman GF/F). Filters were then placed inside a combusted glass petri dish, wrapped in foil, and immediately frozen. A blank filter was also prepared at each sampling point. Filters were later thawed and dried $\left(60^{\circ} \mathrm{C}\right.$; overnight $)$ before encapsulation into $9 \times 10 \mathrm{~mm}$ tin capsules. Measurements for POC quantification were performed by the University of California Davis Stable Isotope Facility. POC filtrates were transferred into combusted glass vials, acidified with $150 \mu \mathrm{l}$ of a $25 \%$ phosphoric acid solution and measured for DOC using high temperature catalytic oxidation on a Shimadzu TOC- $\mathrm{V}_{\mathrm{CSH}}$ with platinized aluminum catalyst. Sample concentrations were determined alongside potassium hydrogen phthalate standards and consensus reference materials provided by the DOC-CRM program (www.rsmas. miami.edu/groups/biogeochem/CRM.html).

\section{EXTRACTION OF DOMP}

Upon entering stationary phase, cells were removed by centrifugation at either 878 RCF (diatom cultures) or 10,751 RCF (cyanobacteria cultures) for $15 \mathrm{~min}$, followed by gentle filtration $(0.1 \mu \mathrm{m}$; Whatman Polycap 36 TC capsule filter). Filtrates were then stored briefly in the dark at $4^{\circ} \mathrm{C}$ until solid-phase extraction (SPE). Material obtained via SPE constitutes $20-60 \%$ of the total DOC in marine DOM (Dittmar et al., 2008), encompassing a large amount of organic substrate available to heterotrophic bacterioplankton. Media controls were processed and stored alongside the culture samples. Filtrates were acidified to $\mathrm{pH} 2-3$ by addition of trace metal grade hydrochloric acid and organic matter was extracted onto ISOLUTE C18(EC) SPE columns (0.5 g, Biotage) at a rate of $1 \mathrm{ml} / \mathrm{min}$. SPE columns were preconditioned with $5 \mathrm{ml}$ HPLC-grade methanol followed by $10 \mathrm{ml}$ ultrapure water. After sampling, mineral salts were washed from the columns with acidified ultrapure water $(\mathrm{pH} 2-3)$ at a flow rate of $1 \mathrm{ml} / \mathrm{min}$. Organic matter was recovered by gravity elution using 10 column volumes of acidified HPLC-grade methanol ( $\mathrm{pH} 2-3$ ). Samples were concentrated to a small volume by rotary evaporation, and then taken to dryness under filtered, high purity nitrogen. Samples were resuspended in $156 \mu \mathrm{l}$ of methanol, and stored briefly in combusted amber vials at $4^{\circ} \mathrm{C}$ in the dark prior to chemical analysis. A $3 \mu \mathrm{l}$ subsample of each was placed onto a combusted $25 \mathrm{~mm}, 0.7 \mu \mathrm{m}$ glass fiber filter (Whatman GF/F), and submitted for POC analysis to quantify the organic carbon recovered by SPE.

\section{CHROMATOGRAPHY AND MASS SPECTROMETRY}

Chromatographic and spectrometric analyses were performed using an Agilent 1200 series high-performance liquid chromatograph coupled to an Agilent 6130 (single quadrupole) mass spectrometer. Organic extracts were separated on a ZORBAX SB-C18 column (Agilent; $3.5 \mu \mathrm{m} 4.6 \times 150 \mathrm{~mm}$ ) eluted at $0.8 \mathrm{ml} \mathrm{min} \mathrm{m}^{-1}$ using a linear gradient ( $\%$ solvent $\mathrm{A}, \%$ solvent $\mathrm{B}$, minutes): 100 , 0,$0 ; 20,80,31.25 ; 0,100,43.75 ; 0,100,64$, where solvent $A$ is aqueous formic acid $(0.1 \%)$ and solvent $\mathrm{B}$ is methanolic formic acid $(0.1 \%)$. Mass spectrometry was performed using an atmospheric electrospray ionization (ESI) source. Drying gas was set at $11.5 \mathrm{l} \mathrm{min}^{-1}$ and $300^{\circ} \mathrm{C}$, the nebulizer was at $60 \mathrm{psig}$, and capillary voltage was set to $4000 \mathrm{~V}$. Data was obtained in the positive ion mode from $100-2000 \mathrm{~m} / z$ with a 4.0 fragmentor, 150 threshold, and 0.1 step size. A tune solution containing five standard compounds (117-2122 $\mathrm{m} / \mathrm{z}$ ) was used to determine mass accuracy of the instrument prior to analysis. Mass accuracy in this size range was found to always be within a tolerance of $0.2 \mathrm{Da}$.

Mass spectral data was analyzed using MZmine 2 molecular profiling software (Pluskal et al., 2010). Ions with signal intensity at least 5-fold greater than the maximum noise level were identified using a centroid mass detector. Chromatograms were 
then built from the raw data using a retention time tolerance of $\pm 5 \mathrm{~s}$, and a mass tolerance of $\pm 0.3 \mathrm{~m} / \mathrm{z}$. Alignments were made to correct for small shifts in retention times between samples and individual peaks were identified by setting a minimum acceptable intensity (5-fold greater than the noise level) and duration ( $5 \mathrm{~s})$ to remove noise within each chromatogram, and also by searching for local minima within each chromatogram. Adduct peaks $\left([\mathrm{M}+\mathrm{Na}]^{+},[\mathrm{M}+2 \mathrm{Na}-\mathrm{H}]^{+},\left[\mathrm{M}+\mathrm{H}_{2} \mathrm{PO}_{4}\right]^{+},\left[\mathrm{M}+\mathrm{HSO}_{4}\right]^{+}\right)$ and isotopic peaks were identified and removed within a retention time tolerance of $\pm 1.42 \mathrm{~s}$, and a mass tolerance of $\pm 0.2 \mathrm{~m} / \mathrm{z}$. Additional adduct peaks for Prochlorococcus $\left(\left[\mathrm{M}+\mathrm{NH}_{4}\right]^{+}\right)$and both Synechococcus and diatoms $\left([\mathrm{M}+\mathrm{K}]^{+}\right)$were identified and removed due to the presence of these chemical species in the media types used to grow these strains. Constraints were placed on the intensity ratio of identified isotope pairs based on the minimum $((\mathrm{M}-1) / 30)$ and maximum $((\mathrm{M}-3) / 14)$ number of carbon atoms for a given mass. Sample feature lists were then aligned and gaps were filled in using a secondary threshold of 3-fold greater than the noise to identify common peaks that fell just below the initial strict threshold. A feature was defined as a unique $\mathrm{m} / \mathrm{z}$ at a specific retention time, thus multiple features could share a specific $m / z$ or retention time, but never both. While the possibility of distinct metabolites sharing identical retention times and $\mathrm{m} / \mathrm{z}$ values within the tolerance levels mentioned above cannot be ruled out, the use of two independent parameters (polarity and mass) to designate $\mathrm{DOM}_{\mathrm{P}}$ features reduces the likelihood of falsely identifying common features.

Biological triplicates of each strain were first compared against triplicate media controls to distinguish material produced by the organism from any background material, including DOM present in the seawater medium used to cultivate each strain. Features were considered to be associated with a particular organism only if they were present in all three biological replicates of that strain and absent in all three replicate controls of the appropriate media type. Removal of features present in sterile media controls reduced the possibility of differences arising due to variations in growth media (i.e., Pro99 medium vs. L1 medium). Features were also removed if they were present in any blank samples, including triplicate instrument blank injections of pure methanol and triplicate processing blanks created by rinsing and eluting pre-cleaned resins without any prior sample loading. Feature lists for each organism were then aligned to identify both common and unique features among the eight strains tested. Aligned feature lists were also used to investigate intensity level differences among features common to multiple samples.

To provide a rigorous analysis of the similarity between all cultures, an aligned feature list containing all the features detected in every replicate was created and converted into a binary matrix where each column represented an individual culture and each row a feature present in at least one culture. Multiplying this matrix by its transpose created a second matrix where each element was the number of features common to each pairwise culture comparison. The matrix was then normalized by the total number of features present in each pairwise comparison. This normalized similarity matrix was used to quantify the similarity of feature lists and their parent strains, and to generate a cluster diagram as a visual representation of $\mathrm{DOM}_{\mathrm{P}}$ similarity among strains. The number of features shared by any two cultures was divided by the sum of features present in those cultures to generate a percent similarity value for all pairwise sample combinations.

\section{RESULTS}

We employed liquid chromatography coupled to low-resolution mass spectrometry to characterize DOM produced by eight marine phytoplankton strains grown in axenic batch cultures. We determined this approach to be of sufficient mass resolution based on elemental analyses of DOM using ultrahigh-resolution mass spectrometry that show the following four prominent, reoccurring mass differences: $14.00156 \mathrm{Da}\left(\mathrm{CH}_{2}\right), 2.0157 \mathrm{Da}$ (double bond/ring series), $1.0034 \mathrm{Da}\left({ }^{13} \mathrm{C}\right.$ and $\left.{ }^{12} \mathrm{C}\right)$, and $0.0364 \mathrm{Da}(\mathrm{C}=\mathrm{O}$ vs. $\left.\mathrm{CH}-\mathrm{CH}_{3}\right)$. All of these mass differences can be distinguished using the mass resolution of the instrument in our study, except for $0.0364 \mathrm{Da}$. This final mass difference would also likely lead to shifts in retention time that can be resolved by HPLC however, and would therefore be detected as distinct features in our data set. Indeed, we analyzed DOM isolated from Prochlorococcus str. MED4 and its corresponding medium control using identical chromatography coupled to Fourier-transform ion cyclotron resonance mass spectrometry (FT-ICR-MS). Processing the resulting data using an appropriate mass resolution $(2 \mathrm{ppm})$ revealed only a modest increase in the number of total DOM features identified in this sample when compared to results obtained using low-resolution mass spectrometry ( 364 features compared to the 346 features reported in this study; FT-ICR-MS data not shown). Equal sample volumes were injected to minimize differences in signal-to-noise between these analyses.

All eight of the marine phytoplankton strains analyzed produced DOM containing hundreds of extracellular hydrophobic features recovered by SPE and detected by HPLC-ESI-MS (Table 1 and Supplementary File 1). Final cell densities and organic carbon production for each replicate are detailed in Table 2 . A variable portion (5-25\%) of the organic carbon produced by each phytoplankton strain was released as extracellular DOM where it might be accessible to heterotrophic microbes in a natural setting. The majority of the features recovered were consistently associated with only one of the strains tested, while a relatively small subset appeared to be produced by a diverse range of organisms. Of the 2032 features detected in culture samples, ranging from 104$1466 \mathrm{~m} / \mathrm{z}$, the majority (1633 features, or $80 \%$ ) were unique to a particular strain; only a few ( 6 features, or $0.3 \%$ ) were found in all eight. Some variation in feature composition was also found among biological replicates for all strains (Table 1) - possibly a result of uncontrollable differences in growth conditions and/or small variations in growth stage at the time of processing. On average, $43 \%$ of the features for a given set of triplicates were found in all three, while $24 \%$ were found in two out of the three, and the remaining $33 \%$ were unique to one replicate. On average, $61 \%$ of the features in a given replicate were also present in the other two replicates. DOM $\mathrm{P}$ composition of the different strains was compared using two approaches. First, only those features common to all three replicates for a given strain were considered produced by that strain. These features were then compared among all eight strains to stringently identify both common and 
Table 2 | Biomass and organic carbon production by phytoplankton cultures tested in this study.

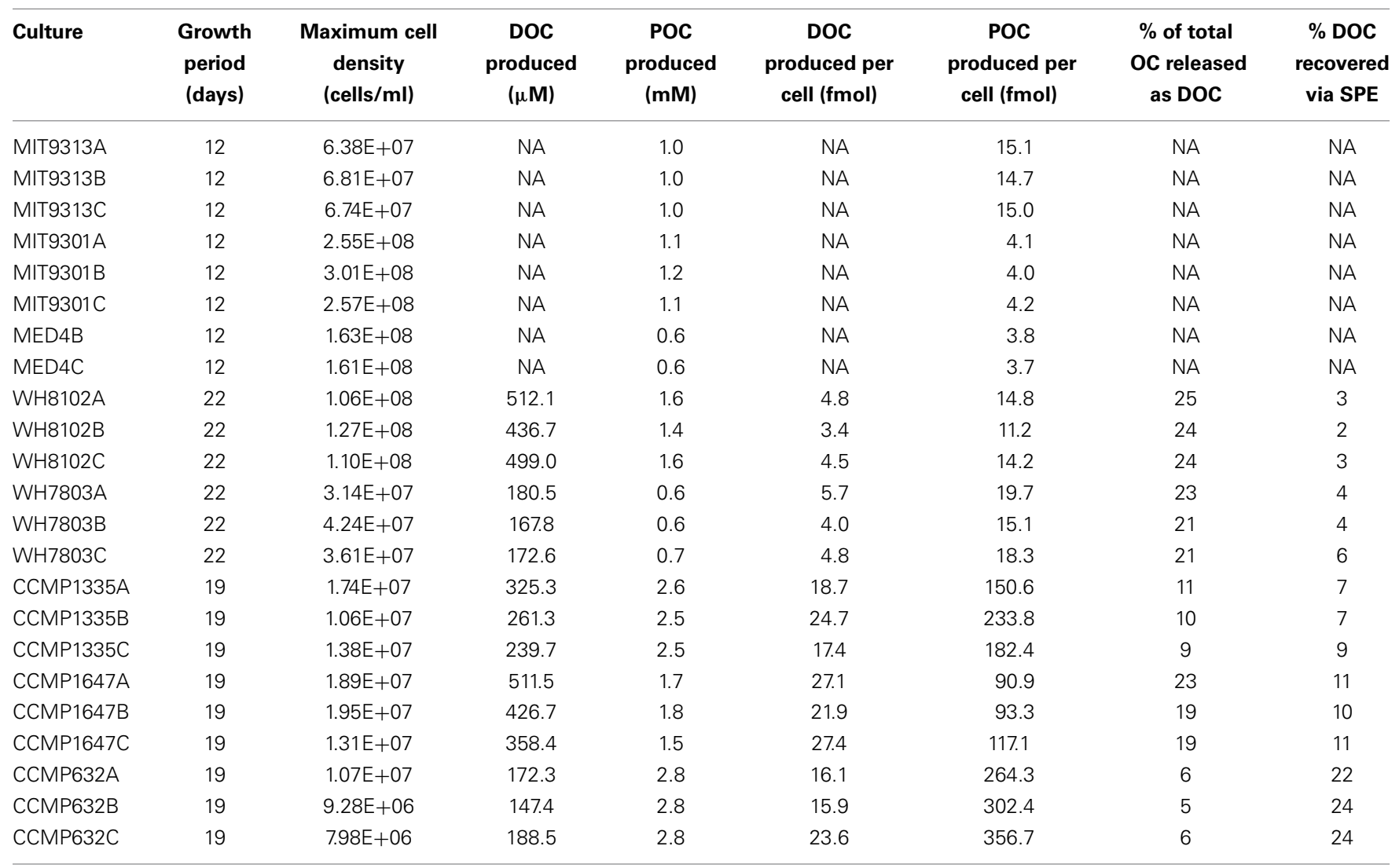

Organic carbon values are background subtracted using media controls.

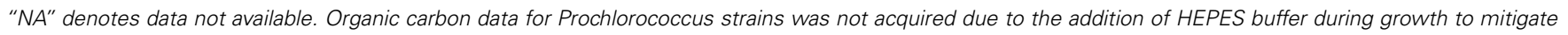
pH changes.

unique features that were consistently associated with each strain. A second approach employed all features detected in any replicate to generate a similarity matrix for running all possible pairwise comparisons, treating all replicates as individual samples. Both of these approaches identified a similar connection between the phylogenetic relationship of the phytoplankton strains tested and the chemical composition of the DOM they produced.

\section{PROCHLOROCOCCUS}

HPLC-ESI-MS detected 577, 673, and 463 features in samples from strains MIT9313, MIT9301, and MED4, respectively. Purity broth tests revealed subsequent heterotrophic contamination in one of the MED4 replicate cultures; therefore this sample was removed from all analyses (see N/A in Table 1). Approximately $40 \%$ of the features associated with each Prochlorococcus strain were detected in all replicates of that strain (Table 1). MIT9313 replicates had the least agreement of all the strains in this study (Figure 1A). Prochlorococcus-derived $\mathrm{DOM}_{\mathrm{P}}$ generally consisted of small, non-polar material, with the majority of features detected between $200-500 \mathrm{~m} / z$ and $20-50 \mathrm{~min}$, when the mobile phase composition was between 51 and 100\% methanol (Figure 2).

Of the total Prochlorococcus-derived features detected in this study, 13\% were produced by all three strains. High-light adapted strains MIT9301 and MED4 were the most similar Prochlorococcus strains, sharing $34 \%$ of their features. Low-light adapted strain MIT9313 shared approximately $22 \%$ of its features with both high-light adapted strains (Figure 3A). Unique features (as much as $52 \%$ of the total) were identified in all three strains. Comparing all replicates as individual samples revealed that biological replicates were generally more alike $(27-67 \%$ similar) than cultures of different strains (12-41\% similar), although both MED4 samples (MED4B and MED4C) had greater similarity to replicates of MIT9301 than to each other (Table 3).

\section{SYNECHOCOCCUS}

HPLC-ESI-MS detected 773 and 434 features in samples from strains WH8102 and WH7803, respectively. Approximately one half to three quarters of the features associated with each Synechococcus strain were detected in all three replicates of that strain (Table 1). The agreement among biological replicates of WH7803 was representative of the average agreement among replicates for all of the strains tested (Figure 1B). The majority of Synechococcus-derived features were detected between 150 $500 \mathrm{~m} / \mathrm{z}$ and $12-50 \mathrm{~min}$, when the mobile phase composition was between 31 and 100\% methanol (Figure 2). Of the total Synechococcus-derived features detected in this study, $14 \%$ were found associated with both strains. Unique features (as much 


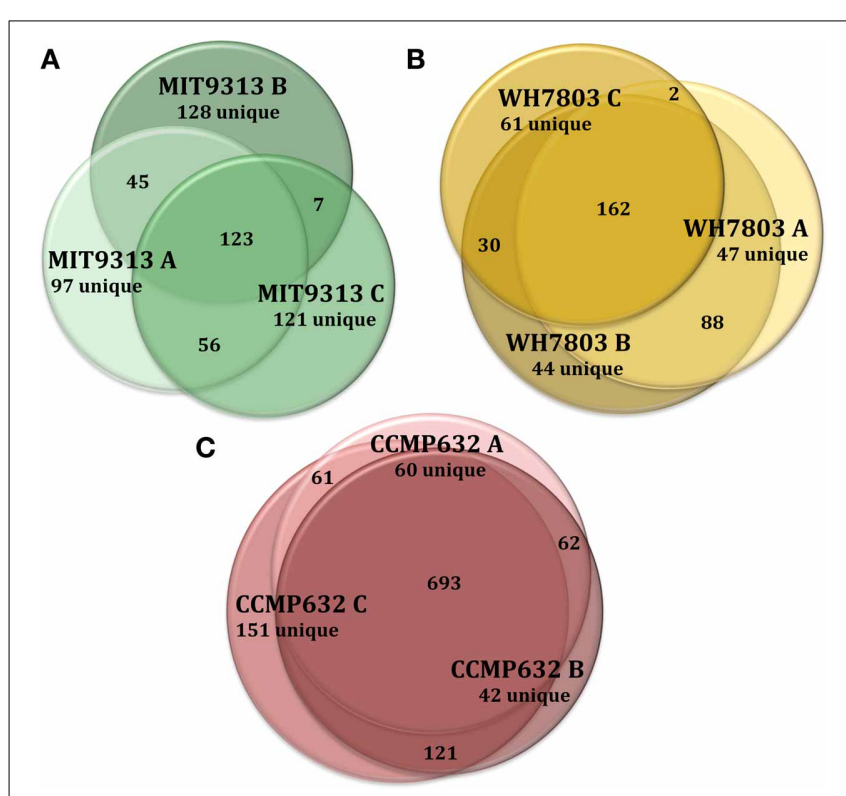

FIGURE 1 | Venn diagrams showing the degree to which triplicate cultures of representative phytoplankton strains share $D O M_{P}$ features. Each culture is represented by a circle, the area of which is proportional to the total number of features identified in that sample. The degree of overlap between circles is proportional to the number of shared features. Prochlorococcus str. MIT9313 replicates had the most variation of any strain tested (A), while P. tricornutum (CCMP632) replicates had the least variation (C). Synechococcus str. WH7803 replicates exhibited an average degree of variation indicative of most strains tested in this study (B). For more detailed information regarding replicate correlations, see Table $\mathbf{3}$

as $83 \%$ of the total) were identified in both strains (Figure 3B). Comparing all replicates as individual samples revealed that all biological replicates were more alike $(42-72 \%$ similar) than cultures of different strains (13-21\% similar) (Table 3).

\section{CYANOBACTERIA}

Among the features consistently detected in Prochlorococcus and Synechococcus samples, 14\% were found associated with all five cyanobacteria strains. The most similar strains between the two groups were Prochlorococcus str. MIT9301 and Synechococcus str. WH8102, sharing 20\% of their features. All Prochlorococcus strains shared more features with each other than with either Synechococcus strain. Synechococcus str. WH7803 shared more features with the other Synechococcus strain tested (WH8102) than with any of the Prochlorococcus strains; however the reverse was not true. Synechococcus str. WH8102 had the most overlap with Prochlorococcus str. MIT9301, sharing 20\%, followed by MIT9313 (15\%) and then WH7803 (14\%). Low-light adapted Synechococcus str. WH7803 was more similar to the low-light adapted Prochlorococcus str. MIT9313 than it was to either of the high-light adapted Prochlorococcus strains. The percent of features shared between all cyanobacteria strain combinations are summarized in Table 4.

Comparing all replicates as individual samples confirmed that Synechococcus str. WH8102 and Prochlorococcus str. MIT9301 were the most similar Synechococcus and Prochlorococcus strains (15-23\% similar) with respect to the DOM features analyzed, and also revealed that WH7803 and the high-light adapted Prochlorococcus strains (MIT9301 and MED4) were the least similar cyanobacteria tested (6-14\% similar). In general, all of the Prochlorococcus strains were more similar to WH8102 (11-23\% similar) than WH7803 (6-14\% similar) (Table 3).

\section{THALASSIOSIRA sp.}

T. pseudonana (CCMP1335) and T. rotula (CCMP1647) were chosen to represent different species of the Thalassiosira genus. HPLC-ESI-MS detected 973 and 1065 features in samples from $T$. pseudonana and T. rotula, respectively. Approximately one half to five sixths of the features associated with each Thalassiosira strain were detected in all three replicates of that strain (Table 1). The majority of Thalassiosira-derived features were detected between $150-700 \mathrm{~m} / \mathrm{z}$ and $20-45 \mathrm{~min}$, when the mobile phase composition was between 51 and 100\% methanol (Figure 2). Of the total Thalassiosira-derived features detected in this study, 11\% were found associated with both strains. Unique features (as much as $82 \%$ of the total) were identified in both strains (Figure 3C). Comparing all replicates as individual samples revealed that all biological replicates were more alike (47-71\% similar) than cultures of different strains (12-15\% similar) (Table 3).

\section{PHAEODACTYLUM TRICORNUTUM}

HPLC-ESI-MS detected 1190 features in P. tricornutum samples. Approximately three fourths of the features associated with each $P$. tricornutum culture were detected in all three replicates (Table 1). P. tricornutum replicates had the most agreement of all the strains in this study (Figure 1C). Phaeodactylumderived $\mathrm{DOM}_{\mathrm{P}}$ generally consisted of larger, more polar material when compared to cyanobacteria $\mathrm{DOM}_{\mathrm{P}}$, with the majority of features detected between $150-1000 \mathrm{~m} / \mathrm{z}$ and $12-45 \mathrm{~min}$, when the mobile phase composition was between 31 and 100\% methanol (Figure 2). Comparing all replicates as individual samples revealed that the biological replicates were more alike (66$73 \%$ similar) than cultures of any other strain $(2-10 \%$ similar) (Table 3).

\section{DIATOMS}

In general, $\mathrm{DOM}_{\mathrm{P}}$ composition was more diverse among the diatom strains than among the cyanobacteria. Among the features consistently detected in the diatom strains tested, only $2 \%$ were found associated with all three strains. T. pseudonana and T. rotula were the most similar diatoms, sharing $11 \%$ of their features. T. rotula and P. tricornutum shared $6 \%$ of their features, while T. pseudonana and P. tricornutum shared 5\% (Figure 3C). A large number of unique features (as much as $87 \%$ of the total) were detected in all three diatom strains. T. pseudonana and $T$. rotula were both more similar to each other than to any of the cyanobacteria strains tested and P. tricornutum was more similar to both Thalassiosira diatoms than to any cyanobacteria strain. Comparing all replicates as individual samples revealed that biological replicates were more alike (47-73\% similar) than cultures of different strains (7-15\% similar), and confirmed that T. pseudonana and $T$. rotula are the most similar diatoms (12$15 \%$ similar), followed by $T$. pseudonana and $P$. tricornutum (7-10\% similar), and T. rotula and P. tricornutum (7-9\% similar) (Table 3). 


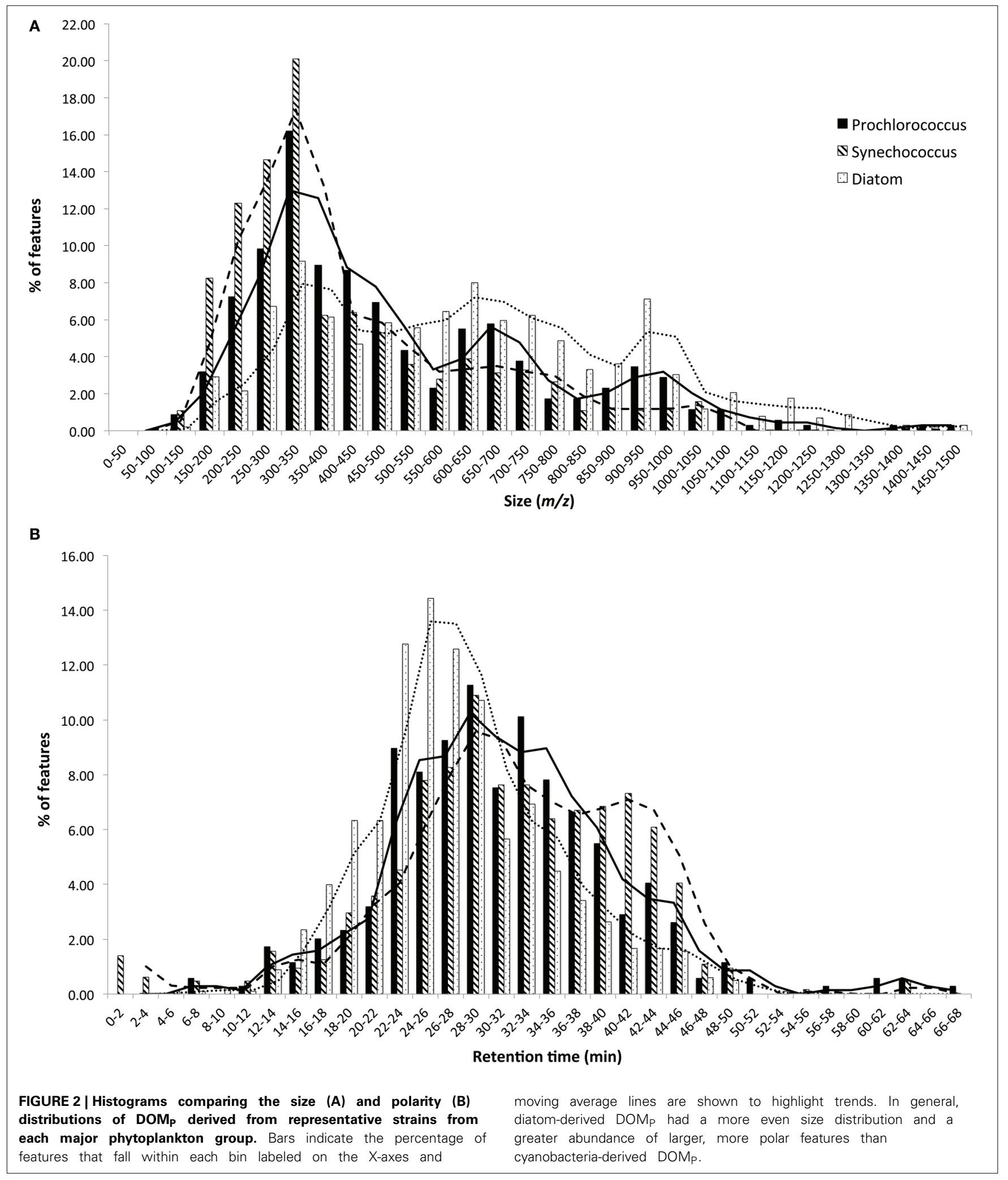

\section{DOMAIN-LEVEL COMPARISONS}

The 2032 DOM $_{P}$ features detected in this study were organized into three groups: those detected in all Prochlorococcus strains, those detected in all Synechococcus strains, and those detected in all diatom strains. Of the 122 features that can be classified this way, only 5\% (6 features) were common to all three groups. Prochlorococcus and Synechococcus were the most similar groups, sharing $14 \%$ of their features, followed by 


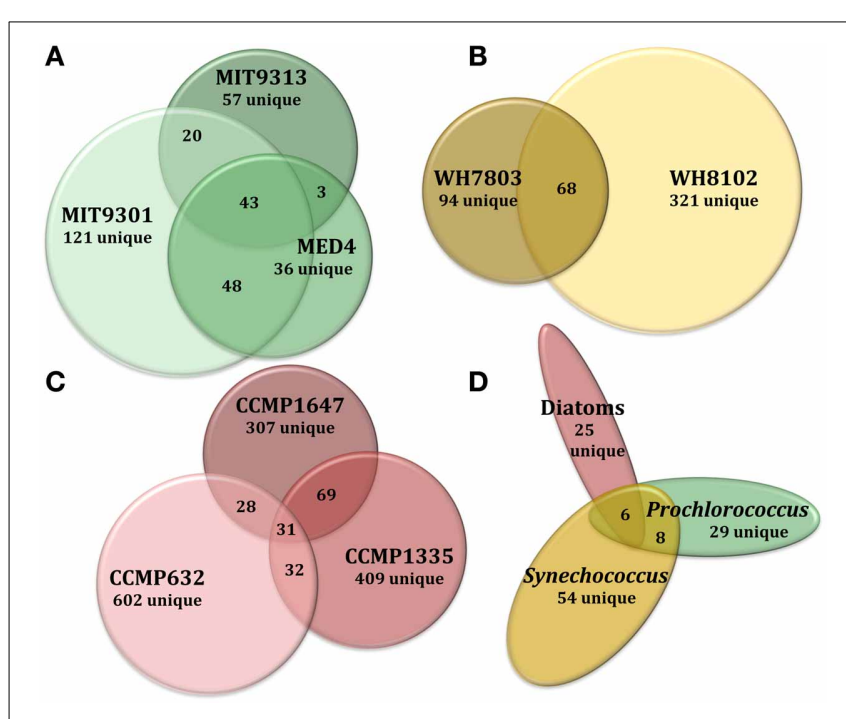

FIGURE 3 | Venn diagrams comparing DOM composition at several levels of phylogenetic variation for all eight phytoplankton strains tested in this study. Features common to all replicate cultures for a given strain are represented by circles or ellipses, the area of which is proportional to the total number of features identified as common for that strain. The degree of overlap between shapes is proportional to the number of shared features between strains of Prochlorococcus (A), Synechococcus (B), and diatoms (C). Features common to each of these 3 broad phytoplankton groupings were also compared (D) to examine variation at the genus and domain levels. For more detailed information regarding percentages of shared DOMp features among different strains, see Table 4

diatoms and Prochlorococcus sharing 10\%, and finally diatoms and Synechococcus sharing 8\% (Figure 3D). All three groups contained a large quantity of features that were unique to that group; the Synechococcus group had the most with 54 unique features, or 79\% of its total. Combining the Prochlorococcus and Synechococcus groups into one cyanobacteria group and comparing this with the diatom group reduced the number of total classifiable features to 39. The same 6 features (now $15 \%$ of the total) mentioned above were common to both groups, while 8 features (21\%) were unique to the cyanobacteria group and 25 features (64\%) were unique to the diatom group.

Comparing all replicates as individual samples revealed that all five cyanobacteria strains were more similar to each other (12-41\% similar) than to any diatom strain tested $(2-12 \%$ similar). Comparisons between cyanobacteria and diatom strains revealed Prochlorococcus str. MIT9301 and T. rotula, and Synechococcus str. WH8102 and T. rotula to be the most similar strains between these two groups, both sharing $8 \%$ of their features. Prochlorococcus str. MED4 and P. tricornutum were the least similar strains, sharing only $1 \%$ of their features. Comparing all replicates as individual samples confirmed that all five cyanobacteria strains were most like T. rotula (4-12\% similar), followed by T. pseudonana (3-8\% similar) and finally P. tricornutum (2-6\% similar). T. pseudonana and P. tricornutum were both more similar to all diatom strains than to any cyanobacteria tested. While T. rotula was most like $T$. pseudonana ( $11 \%$ similar), it had more features in common with Prochlorococcus str. MIT9301 (8\% similar) and Synechococcus str. WH8102 (8\% similar) than with $P$. tricornutum (6\% similar). All three diatom strains were more like Synechococcus str. WH8102 (4-12\% similar) than any other cyanobacteria strain $(2-10 \%$ similar) and more like Prochlorococcus str. MIT9301 (3-10\% similar) than any other Prochlorococcus strain (2-7\% similar). Similarity values are summarized in Table 3, while the percent of features shared between strains are shown in Table 4, alongside their rRNA gene sequence distances. Unique features were detected in all eight phytoplankton strains that were not found in any other strain. P. tricornutum was the most distinct strain with 587 unique features (49\% of its total), while Prochlorococcus str. MED4 was the least distinct with 30 unique features ( $6 \%$ of its total). $\mathrm{DOM}_{\mathrm{P}}$ composition was most similar at the clade-level (14-34\% of features in common) and least similar at the domain-level (1-8\% of features in common).

Molecular weight and polarity distributions of $\mathrm{DOM}_{P}$ were analyzed for additional connections between $\mathrm{DOM}_{\mathrm{P}}$ composition and phytoplankton phylogeny. While all eight strains produced low-molecular-weight $(\leq 1466 \mathrm{~m} / \mathrm{z})$ material over a broad polarity spectrum, cyanobacteria-derived $\mathrm{DOM}_{\mathrm{P}}$ was generally comprised of smaller, less polar features when compared to diatom-derived $\mathrm{DOM}_{\mathrm{P}}$ (Figure 2). P. tricornutum cultures in particular produced large polar DOM, while $T$. rotula produced smaller DOM that more closely resembled cyanobacterial profiles. The low-light adapted Synechococcus str. WH7803 produced slightly larger DOM, resembling centric diatom profiles.

\section{ORIGIN OF ISOLATION}

While much of the observed variation in $\mathrm{DOM}_{\mathrm{P}}$ composition appeared related to producer phylogeny, the data also suggested connections between the composition of $\mathrm{DOM}_{\mathrm{P}}$ and the locations from which these strains were originally isolated (Table 5). Among the diatoms tested, the $\mathrm{DOM}_{\mathrm{P}}$ composition of $P$. tricornutum was found to be more similar to that of T. pseudonana, than to that of $T$. rotula. Both $P$. tricornutum and $T$. pseudonana were isolated from the North Atlantic and under lower temperature conditions than T. rotula, which was isolated from the Mediterranean Sea. We also found that $\mathrm{DOM}_{\mathrm{P}}$ derived from Prochlorococcus str. MED4 was more compositionally similar to that of $T$. rotula (the only other strain isolated from the Mediterranean Sea) than to either of the other diatom strains tested. Additionally, $\mathrm{DOM}_{\mathrm{P}}$ derived from Prochlorococcus str. MIT9313 as well both of the Synechococcus strains tested was more similar to that of Prochlorococcus str. MIT9301 than to that of Prochlorococcus str. MED4. MIT9301, MIT9313, and both Synechococcus strains were all isolated from the Sargasso Sea and MIT9313 and MIT9301 were both isolated from deeper depths than MED4. Prochlorococcus str. MIT9301 and Synechococcus str. WH8102 had the highest correlation in $\mathrm{DOM}_{\mathrm{P}}$ composition between the two cyanobacteria groups. These two strains were originally isolated from the lowest latitudes and most pelagic locations of all the strains tested in this study (Table 5).

\section{ABUNDANCE OF COMMON FEATURES}

Although strictly quantitative assessments within a sample are not feasible due to uncertainties in ionization efficiency in ESI, if we assume that matrix effects are minimal and that abundance 


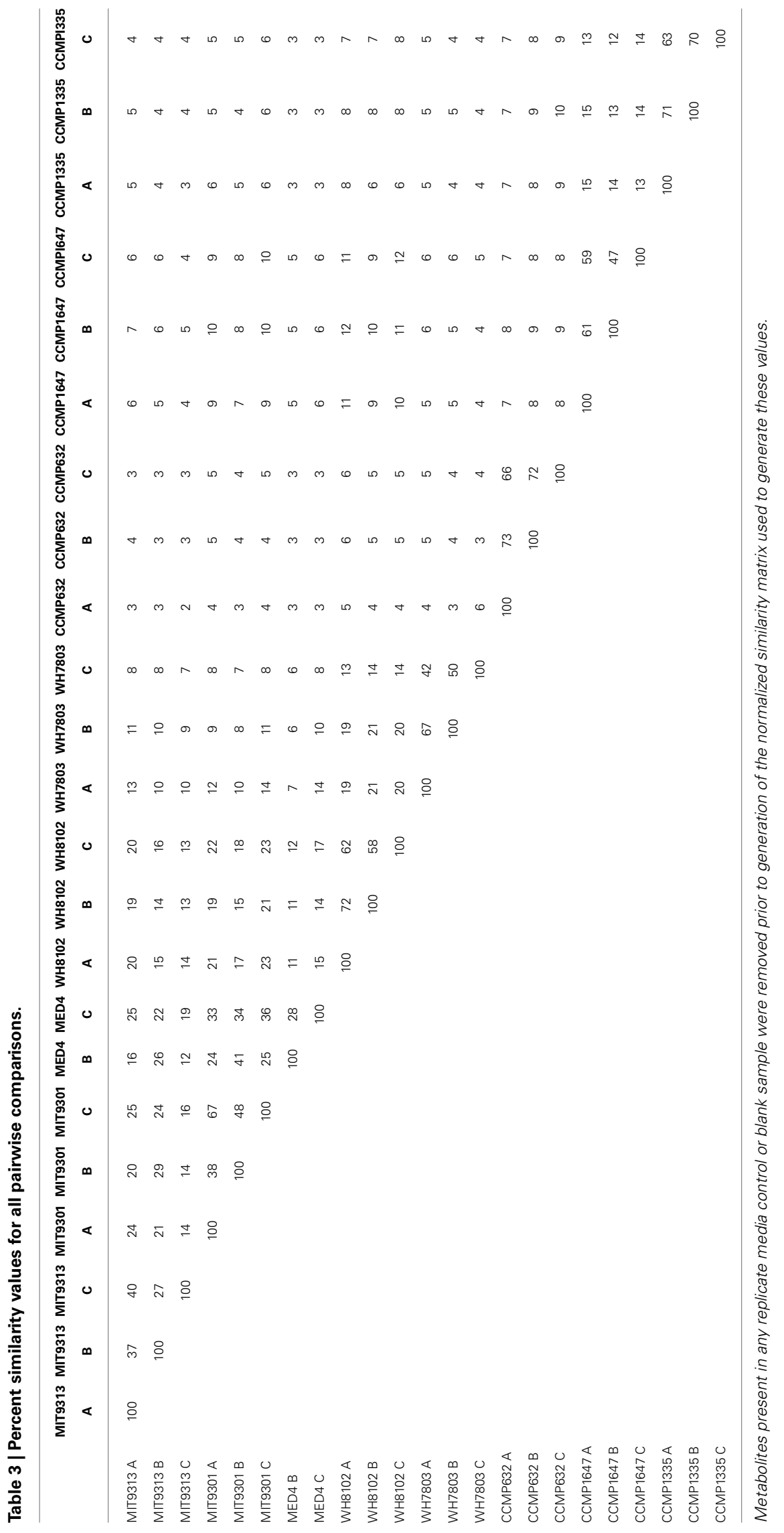


Table 4 | The percent of features shared among all pairwise strain comparisons (top) alongside sequence distances based on small subunit rRNA gene sequences (bottom in bold) for the eight phytoplankton strains tested in this study.

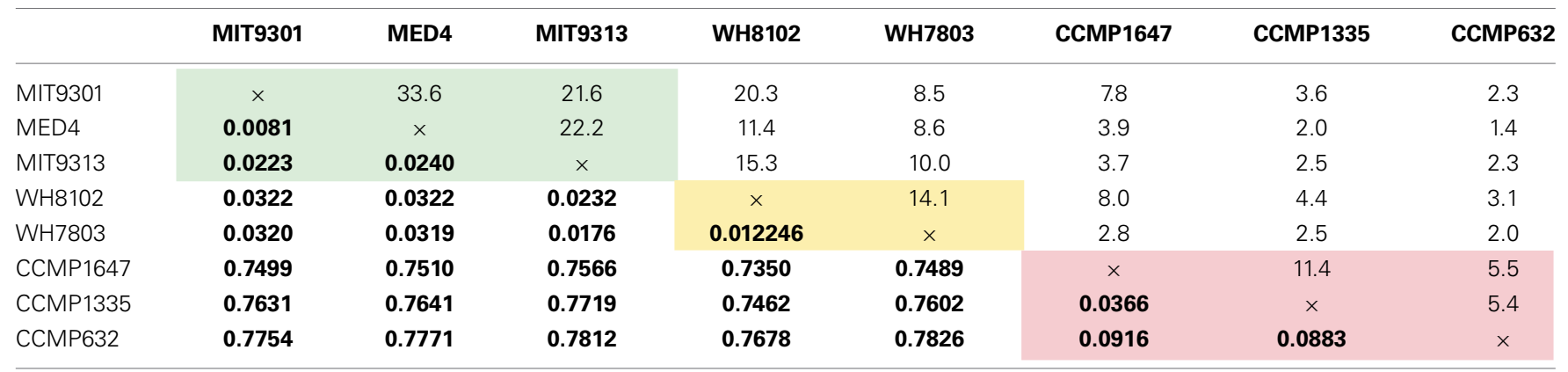

Features used in percentage calculations were considered to be produced by a strain only if they were present in all replicates for that strain and absent in all media controls and blanks. Comparisons between Prochlorococcus strains are highlighted in green, comparisons between Synechococcus strains are highlighted in yellow, and comparisons between diatom strains are highlighted in red.

Aligned 16S and 18S rRNA gene sequences were obtained from the SILVA SSURef database release 108, 19.08.2011. The distance matrix was constructed from 1,349 sites using the unweighted LogDet algorithm in Phylip version 3.6.8. See Rocap et al. (2002); Sorhannus (2004) and Kettler et al. (2007) for more information regarding phylogenetic relationships within these groups.

scales linearly with signal intensity, then the intensity level of features detected in multiple samples offers semi-quantitative information regarding common features associated with different phytoplankton strains. Comparing a particular strain with its respective medium control can identify material present in the seawater-based medium that were also produced by the organism as well as highlight material consumed by phytoplankton during growth.

Scatter plots of signal intensity provide a visual representation of semi-quantitative differences among features common to multiple samples (Figure 4). Intensity comparisons above and below a threshold of 4 -fold were chosen because the majority of common features ( $93 \%$ on average) among all replicate samples and blanks were within a 4 -fold intensity difference (Figure 4A). A representative comparison of common features found in a culture sample (Prochlorococcus str. 9301 replicate C) and its respective media control (Pro99 medium replicate C) demonstrates that while the majority of features $(95 \%$ on average) are within a 4 -fold intensity difference, there was material present in the medium produced (dots above the upper 4:1 line) and consumed (dots below the lower 4:1 line) during phytoplankton growth (Figure 4B). Pairwise comparisons of different strains exhibited greater intensity differences than among replicates, and the degree of intensity differences between strains varied widely. On average, $91 \%$ of common features among different Prochlorococcus strains were within a 4-fold intensity difference (Figure 4C). An average of $82 \%$ of common features among the different Synechococcus strains were within a 4 -fold intensity difference, while $77 \%$ of common features were within a 4 -fold intensity difference among the different diatom strains. On average, $84 \%$ of features common to Prochlorococcus and Synechococcus were within a 4-fold intensity difference, while an average of 75 and $68 \%$ of common features were within a 4 -fold intensity difference when comparing Prochlorococcus to diatoms and Synechococcus to diatoms, respectively (Figures $4 \mathrm{D}-\mathrm{F}$ ).

\section{DISCUSSION}

Untargeted metabolomic profiling of $\mathrm{DOM}_{\mathrm{P}}$ derived from eight model marine phytoplankton strains suggests that producer phylogeny may be an important factor in determining the chemical composition of marine DOM. While a large proportion $(80 \%)$ of the features detected in this study were unique to a particular strain, cluster analyses based on phylogeny and $\mathrm{DOM}_{\mathrm{P}}$ composition (by either pooling common features among replicates or analyzing each replicate separately) revealed that phylogenetically related strains tended to produce organic compound suites of a more similar chemical composition (Figure 5). This relationship was found to exist at the domain, order, genus, species, and clade level, and indicates that variations in $\mathrm{DOM}_{\mathrm{P}}$ composition can reflect phylogenetic relationships among the producing organisms, a potential consequence of connections between their genomes and exometabolomes (defined here as $\left.\mathrm{DOM}_{\mathrm{P}}\right)$. Chemical trends in the $\mathrm{DOM}_{\mathrm{P}}$ composition of the phytoplankton strains indicate that eukaryotic phytoplankton may contribute a greater amount of higher molecular weight material over a broad polarity range when compared to cyanobacteria, and that both the molecular weight and polarity of $\mathrm{DOM}_{\mathrm{P}}$ components may also vary according to biological origin.

The degree of variation in ion intensity among common features was also found to parallel phylogenetic variation. Under the growth conditions tested here, closely related strains not only produced DOM of similar composition, but also produced common components in similar relative abundance (Figure 4). Semi-quantitative analysis in this fashion also provides an opportunity to examine growth dynamics and mixotrophic activity of marine phytoplankton. Many marine phytoplankton have been shown to exhibit mixotrophic tendencies (Cerón García et al., 2006; Bronk et al., 2007; Baran et al., 2011; Gómez-Pereira et al., 2012) and features found in greater abundance in media controls compared to their respective $\mathrm{DOM}_{\mathrm{P}}$ provide interesting targets for further chemical identification, as these features likely 
Table 5 | Isolation and niche information for the eight phytoplankton strains tested in this study.

\begin{tabular}{|c|c|c|c|c|}
\hline Strain & $\begin{array}{l}\text { Isolation } \\
\text { site }\end{array}$ & $\begin{array}{l}\text { Isolation } \\
\text { depth (m) }\end{array}$ & $\begin{array}{c}\text { Growth } \\
\text { temp. }\left({ }^{\circ} \mathrm{C}\right)\end{array}$ & $\begin{array}{l}\text { Light } \\
\text { optima }\end{array}$ \\
\hline \multicolumn{5}{|c|}{ Prochlorococcus } \\
\hline MIT9313 & $\begin{array}{l}37.5002 \mathrm{~N} 68.2334 \mathrm{~W} \\
\text { Sargasso Sea }\end{array}$ & 135 & $18-22$ & Low \\
\hline MIT9301 & $\begin{array}{l}\text { 34.1667N 66.3000W } \\
\text { Sargasso Sea }\end{array}$ & 90 & $18-22$ & High \\
\hline MED4 & $\begin{array}{l}35.0000 \mathrm{~N} 20.0000 \mathrm{E}^{\mathrm{a}} \\
\text { Mediterranean Sea }\end{array}$ & 5 & $18-22$ & High \\
\hline \multicolumn{5}{|c|}{ Synechococcus } \\
\hline WH8102 & $\begin{array}{l}22.4950 \mathrm{~N} 65.6000 \mathrm{~W} \\
\text { Sargasso Sea }\end{array}$ & Near surface & $22-26$ & High \\
\hline WH7803 & $\begin{array}{l}33.7423 \mathrm{~N} 67.4913 \mathrm{~W} \\
\text { Sargasso Sea }\end{array}$ & 25 & $22-26$ & Low \\
\hline \multicolumn{5}{|l|}{ Diatoms } \\
\hline P. tricornutum & $\begin{array}{l}54.0000 \mathrm{~N} 04.0000 \mathrm{~W}^{\mathrm{a}} \\
\text { Eastern N. Atlantic }\end{array}$ & Near surface & $18-22$ & High \\
\hline T. rotula & $\begin{array}{l}\text { 40.7500N 14.3300E } \\
\text { Mediterranean Sea }\end{array}$ & Near surface & $18-22$ & High \\
\hline T. pseudonana & $\begin{array}{l}40.7560 \mathrm{~N} 72.8200 \mathrm{~W} \\
\text { Western N. Atlantic }\end{array}$ & Near surface & $11-16$ & High \\
\hline
\end{tabular}

${ }^{a}$ Approximate isolation coordinates.

Data compiled from ncma.bigelow.org.

represent compounds present in the growth medium that were consumed by phytoplankton cells during growth (e.g., features below the 4:1 line in Figure 4B).

Our data also lends some support for a possible connection between $\mathrm{DOM}_{\mathrm{P}}$ composition and habitat. Mass spectrometric analysis revealed similarities in $\mathrm{DOM}_{\mathrm{P}}$ composition among strains isolated from similar habitats, suggesting that adaptations to a particular environment may also influence DOM production by marine phytoplankton. Although many of the strains employed here have been in laboratory culture for many years, one strain (MED4) has been shown to have an extremely stable genome (Osburne et al., 2010), which we suspect is a characteristic of this phytoplankton group. Thus, these adaptations have likely been retained in current isolates. Genomic and metagenomic studies have shown that environmental conditions can shape the gene content of marine bacteria (Martiny et al., 2009; Coleman and Chisholm, 2010). Potential connections between habitat and $\mathrm{DOM}_{\mathrm{P}}$ composition appear to be worthy of additional investigation in the field, and many more samples will need to be analyzed to adequately test this hypothesis.

The protocols described here allow for the creation of a spectral database of $\mathrm{DOM}_{\mathrm{P}}$ characteristics and for identification of target features of interest for additional chemical analyses, such as nuclear magnetic resonance spectroscopy and high-resolution mass spectrometry (Aluwihare et al., 1999; Soule et al., 2010). Spectral data can be compared against existing metabolomic databases for compound identification (Tautenhahn et al., 2012a,b). Each phytoplankton strain that we tested produced and released a complex suite of $\mathrm{DOM}_{\mathrm{P}}$ containing hundreds to thousands of hydrophobic features. As the effort required to

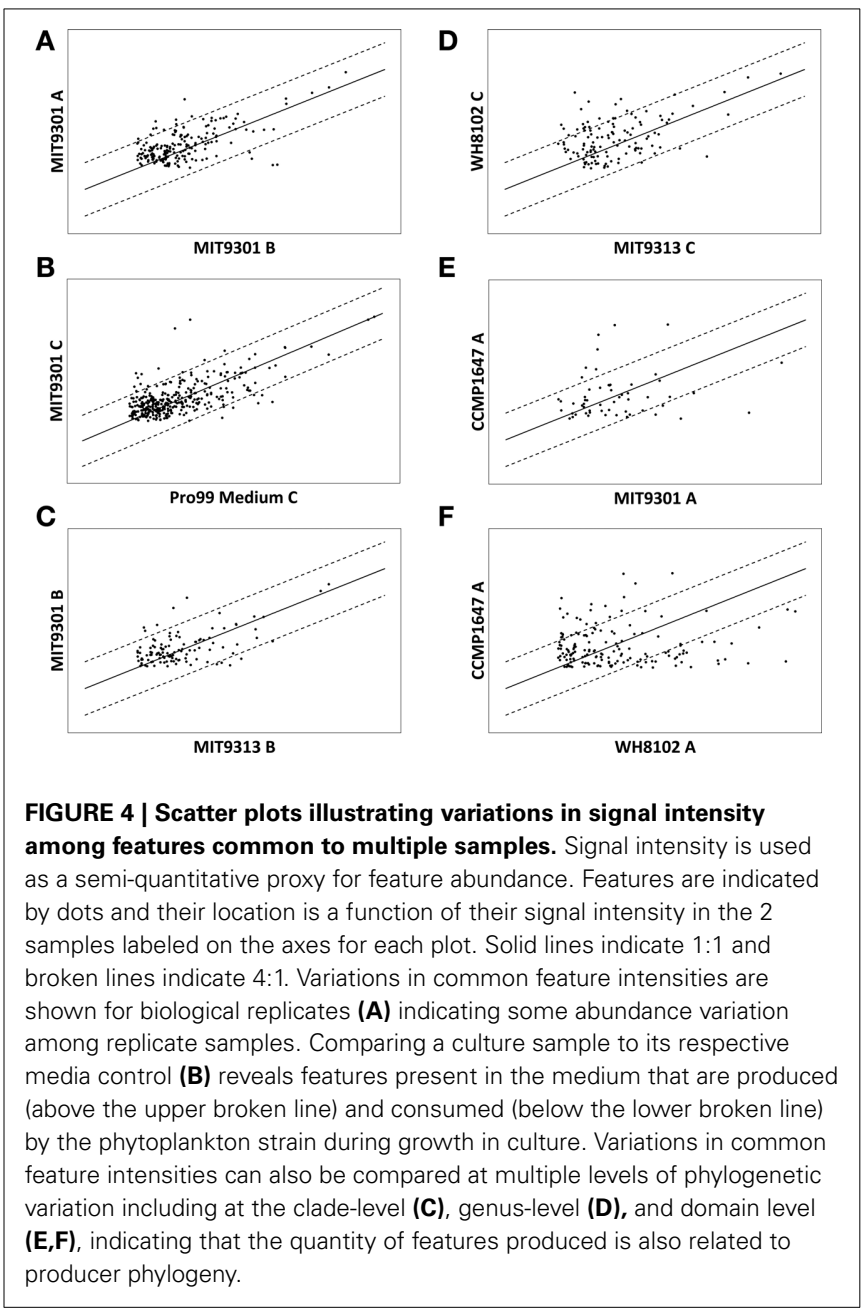

definitively identify a single feature derived from an untargeted metabolomics approach is not trivial (Bowen and Northen, 2010; Schwarz et al., 2013), it is useful to target organic compounds worthy of additional attention. One way to accomplish this task is to organize features into categories based on their presence or absence in particular samples according to phylogenetic grouping. For instance, only six features were found to be common to all of the strains tested here, and likely represent metabolites that are produced by a diverse array of phytoplankton. This relatively short list of features could be likely targets for further chemical characterization. The coupling of $\mathrm{DOM}_{\mathrm{P}}$ analysis as described here with DOM consumption experiments involving heterotrophic bacterioplankton has the potential to yield novel information regarding chemical transformations of DOM and interactions between autotrophic and heterotrophic marine microorganisms.

Differences in $\mathrm{DOM}_{\mathrm{P}}$ composition were generally much greater between strains than among biological replicates of the same strain. However, significant variation was found to exist among replicates (Figure 1). While some of these differences may be attributed to variables in sample processing, this finding more likely indicates that $\mathrm{DOM}_{\mathrm{P}}$ composition is also influenced by factors such as growth conditions, cell density and phase of 


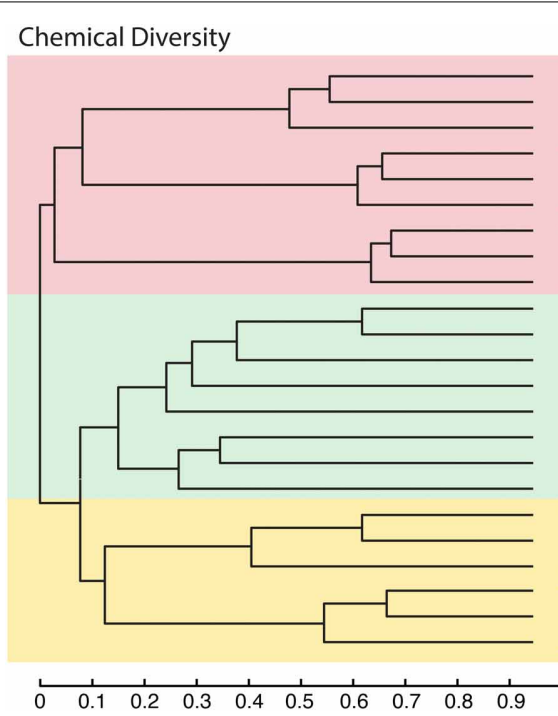

FIGURE 5 | Phylogeny of the eight model phytoplankton strains and the chemical similarity of the DOM they produce show similar relationship patterns. At left is shown a dendrogram created from the normalized similarity matrix of all DOMp features identified in each culture replicate after media subtraction using the unweighted pair group method average (UPGMA). The scale bar corresponds to percent similarity values of DOM composition for all pairwise comparisons as given in Table 3. At right is a schematic representation of the phylogenetic relationships between the 8 organisms based on previous work with ribosomal gene sequences and whole genome comparisons (Rocap et al., 2002; Sorhannus, 2004; Kettler et al., 2007). Branch lengths do not correspond to phylogenetic distances. See Table 4, for information regarding rRNA gene sequence distances. growth. Growth phase in particular has been shown to affect the composition of DOM released by several diatom strains in culture (Barofsky et al., 2009). Our results support this conclusion, and suggest that even subtle shifts in physiology and other (as yet unidentified) parameters may significantly impact the composition of phytoplankton-derived DOM. To provide sufficient material for analysis, it was necessary to grow the cells to late exponential phase; while all replicates behaved similarly and yielded similar cell densities, slight variations in the final growth phase among replicates may have influenced $\mathrm{DOM}_{\mathrm{p}} \mathrm{com}$ position. The five cyanobacteria strains tested in this study all displayed greater $\mathrm{DOM}_{\mathrm{P}}$ variation among replicates than the diatom strains, suggesting that cyanobacteria, and Prochlorococcus in particular, may have been more susceptible to these factors. Under dynamic in-situ conditions, producer phylogeny is likely to be only one of several factors (temperature, light, nutrient availability, growth rate, etc.) influencing the composition of phytoplankton-derived DOM. As the eight strains tested here represent only a small fraction of eukaryotic algal and cyanobacterial diversity grown under controlled conditions, additional studies on an extensive array of marine phytoplankton using continuous cultures or fed batch reactors under a variety of conditions are needed. Further experimentation along these lines will help to determine if marine phytoplankton typically produce DOM suites that reflect their phylogenetic relationships and evaluate how phytoplankton-derived DOM composition varies in response to growth rate and changes in environmental conditions.

Initial results from this study of $\mathrm{DOM}_{\mathrm{P}}$ show that marine phytoplankton can release characteristic suites of organic material and support the notion that phytoplankton phylogeny is a factor in determining DOM composition. Spatial and temporal variations in phytoplankton community structure (over smaller scales such as seasonal phytoplankton blooms or larger scales including gradual shifts due to global climate conditions) may therefore be accompanied by predictable variations in the composition of marine DOM. Compositional differences in DOM have been shown to affect both the relative abundance and activity of particular heterotrophic bacteria groups, suggesting a relationship between DOM composition and heterotrophic bacterioplankton diversity (Cottrell and Kirchman, 2000; RomeraCastillo et al., 2011; Nelson and Carlson, 2012; Sarmento and Gasol, 2012). If additional studies confirm the relationship between DOM composition and producer phylogeny presented here, then phytoplankton diversity could directly impact heterotrophic bacterioplankton diversity in the marine environment via a DOM link.

\section{ACKNOWLEDGMENTS}

We gratefully acknowledge the National Center for Marine Algae and Microbiota, particularly C. Schuman and T. Riggens, for providing phytoplankton strains and media. We also thank V. Starczak, K. Longnecker, M. Bhatia, and R. Boiteau for insightful discussions regarding data analysis, M. Rappé and two reviewers for helpful comments on the manuscript, and C. Johnson for technical assistance with mass spectrometry method development. This research was supported by grants to Daniel J. Repeta and Sallie W. Chisholm from the Gordon and Betty Moore Foundation and funding to Daniel J. Repeta, Edward F. DeLong, and Sallie W. Chisholm from the National Science Foundation Science and Technology Center Award 0424599. This article is a contribution from the Center for Microbial Oceanography: Research and Education (C-MORE). 


\section{SUPPLEMENTARY MATERIAL}

The Supplementary Material for this article can be found online at: http://www.frontiersin.org/journal/10.3389/fmicb.2014. 00111/abstract

\section{REFERENCES}

Aluwihare, L. I., Repeta, D. J., and Chen, R. F. (1999). A comparison of the chemical characteristics of oceanic DOM and extracellular DOM produced by marine algae. MEPS 186, 105-117. doi: 10.3354/meps186105

Alverson, A. J., Beszteri, B., Julius, M. L., and Theriot, E. C. (2011). The model marine diatom Thalassiosira pseudonana likely descended from a freshwater ancestor in the genus Cyclotella. BMC Evol. Biol. 11:125. doi: 10.1186/14712148-11-125

Baines, S. B., and Pace, M. L. (1991). The production of dissolved organic matter by phytoplankton and its importance to bacteria: patterns across marine and freshwater systems. Limnol. Oceanogr. 36, 1078-1090. doi: 10.4319/lo.1991.36. 6.1078

Baran, R., Bowen, B. P., and Northen, T. R. (2011). Untargeted metabolic footprinting reveals a surprising breadth of metabolite uptake and release by Synechococcus sp. PCC 7002. Mol. Biosyst. 7, 3200-3206. doi: $10.1039 / \mathrm{clmb} 05196 \mathrm{~b}$

Barofsky, A., Vidoudez, C., and Pohnert, G. (2009). Metabolic profiling reveals growth stage variability in diatom exudates. Limnol. Oceanogr. Methods 7, 382-390. doi: 10.4319/lom.2009.7.382

Bertilsson, S., Berglund, O., Pullin, M. J., and Chisholm, S. W. (2005). Release of dissolved organic matter by Prochlorococcus. Vie et Milieu 55, 225-232.

Bertilsson, S., and Jones, J. B. Jr. (2003). "Supply of dissolved organic matter to aquatic ecosystems: autochthonous sources," in Aquatic Ecosystems, eds S. E. G. Findlay and R. L. Sinsabaugh (Burlington: Academic Press), 3-24. doi: 10.1016/B978-012256371-3/50002-0

Bjornsen, P. K. (1988). Phytoplankton exudation of organic matter: why do healthy cells do it? Limnol. Oceanogr. 33, 151-154. doi: 10.4319/lo.1988.33.1.0151

Bowen, B. P., and Northen, T. R. (2010). Dealing with the unknown: metabolomics and metabolite atlases. J. Am. Soc. Mass Spectrom. 21, 1471-1476. doi: 10.1016/j.jasms.2010.04.003

Bronk, D. A., See, J. H., Bradley, P., and Killberg, L. (2007). DON as a source of bioavailable nitrogen for phytoplankton. Biogeosciences 4, 283-296. doi: 10.5194/bg-4-283-2007

Carlson, C. A. (2002). "Production and removal processes," in Biogeochemistry of Marine Dissolved Organic Matter, eds D. A. Hansell and C. A. Carlson (San Diego, CA: Academic Press), 91-151. doi: 10.1016/B978-012323841-2/ 50006-3

Cavender-Bares, K. K., Mann, E. L., Chisholm, S. W., Ondrusek, M. E., and Bidigare, R. R. (1999). Differential response of equatorial Pacific phytoplankton to iron fertilization. Limnol. Oceanogr. 44, 237-246. doi: 10.4319/lo.1999.44.2.0237

Cerón García, M. C., Camacho, F. G., Mirón, A. S., Sevilla, J. M. F., Chisti, Y., and Grima, E. M. (2006). Mixotrophic production of marine microalga Phaeodactylum tricornutum on various carbon sources. J. Microbiol. Biotechnol. 16, 689-694.

Coleman, M. L., and Chisholm, S. W. (2010). Ecosystem-specific selection pressures revealed through comparative population genomics. Proc. Natl. Acad. Sci. U.S.A. 107, 18634-18639. doi: 10.1073/pnas.1009480107

Cottrell, M. T., and Kirchman, D. L. (2000). Natural assemblages of marine proteobacteria and members of the Cytophaga-Flavobacter cluster consuming low-and high-molecular-weight dissolved organic matter. Appl. Environ. Microbiol. 66, 1692-1697. doi: 10.1128/AEM.66.4.1692-1697.2000

De Martino, A., Meichenin, A., Kehou Pan, J. S., and Bowler, C. (2007). Genetic and phenotypic characterization of Phaeodactylum tricornutum (Bacillariophyceae) accessions. J. Phycol. 43, 992-1009. doi: 10.1111/j.1529-8817.2007.00384.x

Dittmar, T., Koch, B., Hertkorn, N., and Kattner, G. (2008). A simple and efficient method for the solid-phase extraction of dissolved organic matter (SPE-DOM) from seawater. Limnol. Oceanogr. Methods 6, 230-235. doi: 10.4319/lom.2008.6.230

Engel, A., Handel, N., Wohlers, J., Lunau, M., Grossart, H. P., Sommer, U., et al. (2011). Effects of sea surface warming on the production and composition of dissolved organic matter during phytoplankton blooms: results from a mesocosm study. J. Plankton Res. 33, 357-372. doi: 10.1093/plankt/fbq122
Flombaum, P., Gallegos, J. L., Gordillo, R. A., Rincón, J., Zabala, L. L., Jiao, N., et al. (2013). Present and future global distributions of the marine Cyanobacteria, Prochlorococcus and Synechococcus. Proc. Natl. Acad. Sci. U.S.A. 110, 9824-9829. doi: 10.1073/pnas.1307701110

Fogg, G. E. (1983). The ecological significance of extracellular products of phytoplankton photosynthesis. Bot. Mar. 26, 3-14. doi: 10.1515/botm.1983.26.1.3

Giovannoni, S. J., Hayakawa, D. H., Tripp, H. J., Stingl, U., Givan, S. A., Cho, J.-C., et al. (2008). The small genome of an abundant coastal ocean methylotroph. Environ. Microbiol. 10, 1771-1782. doi: 10.1111/j.1462-2920.2008.01598.x

Giovannoni, S. J., Tripp, H. J., Givan, S., Podar, M., Vergin, K. L., Baptista, D., et al. (2005). Genome streamlining in a cosmopolitan oceanic bacterium. Science 309, 1242-1245. doi: 10.1126/science.1114057

Gómez-Pereira, P. R., Hartmann, M., Grob, C., Tarran, G. A., Martin, A. P., Fuchs, B. M., et al. (2012). Comparable light stimulation of organic nutrient uptake by SAR11 and Prochlorococcus in the North Atlantic subtropical gyre. ISME J. 7, 603-614. doi: 10.1038/ismej.2012.126

Grossart, H. P., and Simon, M. (2007). Interactions of planktonic algae and bacteria: effects on algal growth and organic matter dynamics. Aquat. Microb. Ecol. 47, 163-176. doi: 10.3354/ame047163

Guillard, R. R. L., and Hargraves, P. E. (1993). Stichochrysis immobilis is a diatom, not a chrysophyte. Phycologia 32, 234-236. doi: 10.2216/i0031-8884-32-3-234.1

Hirt, G., Tanner, W., and Kandler, O. (1971). Effect of light on the rate of glycolysis in Scenedesmus obliquus. Plant Physiol. 47, 841-843. doi: 10.1104/pp.47. 6.841

Kettler, G. C., Martiny, A. C., Huang, K., Zucker, J., Coleman, M. L., Rodrigue, S., et al. (2007). Patterns and implications of gene gain and loss in the evolution of Prochlorococcus. PLoS Genet. 3:e231. doi: 10.1371/journal.pgen.0030231

Landa, M., Cottrell, M. T., Kirchman, D. L., Blain, S., and Obernosterer, I. (2013a). Changes in bacterial diversity in response to dissolved organic matter supply in a continuous culture experiment. Aquat. Microb. Ecol. 69, 157-168. doi: 10.3354/ame01632

Landa, M., Cottrell, M. T., Kirchman, D. L., Kaiser, K., Medeiros, P. M., Tremblay, L., et al. (2013b). Phylogenetic and structural response of heterotrophic bacteria to dissolved organic matter of different chemical composition in a continuous culture study. Environ. Microbiol. doi: 10.1111/1462-2920.12242. [Epub ahead of print].

Mague, T., Friberg, E., Hughes, D., and Morris, I. (1980). Extracellular release of carbon by marine phytoplankton; a physiological approach. Limnol. Oceanogr. 25, 262-279. doi: 10.4319/lo.1980.25.2.0262

Martiny, A. C., Huang, Y., and Li, W. (2009). Occurrence of phosphate acquisition genes in Prochlorococcus cells from different ocean regions. Environ. Microbiol. 11, 1340-1347. doi: 10.1111/j.1462-2920.2009.01860.x

McCarren, J., Becker, J. W., Repeta, D. J., Shi, Y., Young, C. R., Malmstrom, R. R., et al. (2010). Microbial community transcriptomes reveal microbes and metabolic pathways associated with dissolved organic matter turnover in the sea. Proc. Natl. Acad. Sci. U.S.A. 107, 16420-16427. doi: 10.1073/pnas.1010732107

Meon, B., and Kirchman, D. L. (2001). Dynamics and molecular composition of dissolved organic material during experimental phytoplankton blooms. Mar. Chem. 75, 185-199. doi: 10.1016/S0304-4203(01)00036-6

Moore, L. R., and Chisholm, S. W. (1995). Comparative physiology of Synechococcus and Prochlorococcus: influence of light and temperature on growth, pigments, fluorescence and absorptive properties. MEPS 116, 259-275. doi: $10.3354 /$ meps116259

Moore, L. R., Coe, A., Zinser, E. R., Saito, M. A., Sullivan, M. B., Lindell, D., et al. (2007). Culturing the marine cyanobacterium Prochlorococcus. Limnol. Oceanogr. Methods 5, 353-362. doi: 10.4319/lom.2007.5.353

Moore, L. R., Post, A. F., Rocap, G., and Chisholm, S. W. (2002). Utilization of different nitrogen sources by the marine cyanobacteria Prochlorococcus and Synechococcus. Limnol. Oceanogr. 47, 989-996. doi: 10.4319/lo.2002.47.4.0989

Moore, L. R., Rocap, G., and Chisholm, S. W. (1998). Physiology and molecular phylogeny of coexisting Prochlorococcus ecotypes. Nature 393, 464-467. doi: $10.1038 / 30965$

Myklestad, S. M. (1995). Release of extracellular products by phytoplankton with special emphasis on polysaccharides. Sci. Total Environ. 165, 155-164. doi: 10.1016/0048-9697(95)04549-G

Nebbioso, A., and Piccolo, A. (2013). Molecular characterization of dissolved organic matter (DOM): a critical review. Anal. Bioanal. Chem. 405, 109-124. doi: 10.1007/s00216-012-6363-2 
Nelson, C. E., and Carlson, C. A. (2012). Tracking differential incorporation of dissolved organic carbon types among diverse lineages of Sargasso Sea bacterioplankton. Environ. Microbiol. 14, 1500-1516. doi: 10.1111/j.14622920.2012.02738.x

Obernosterer, I., and Herndl, G. J. (1995). Phytoplankton extracellular release and bacterial growth: dependence on the inorganic N: P ratio. MEPS 116, 247-257. doi: $10.3354 /$ meps 116247

Olson, R. J., Vaulot, D., and Chisholm, S. W. (1985). Marine phytoplankton distributions measured using shipboard flow cytometry. Deep Sea Res. A Oceanogr. Res. Pap. 32, 1273-1280. doi: 10.1016/0198-0149(85)90009-3

Osburne, M. S., Holmbeck, B. M., Frias-Lopez, J., Steen, R., Huang, K., Kelly, L., et al. (2010). UV hyper-resistance in Prochlorococcus MED4 results from a single base pair deletion just upstream of an operon encoding nudix hydrolase and photolyase. Environ. Microbiol. 12, 1978-1988. doi: 10.1111/j.14622920.2010.02203.x

Palenik, B., Brahamsha, B., Larimer, F. W., Land, M., Hauser, L., Chaln, P., et al. (2003). The genome of a motile marine Synechococcus. Nature 424, 1037-1042. doi: 10.1038 /nature 01943

Partensky, F., Hess, W. R., and Vaulot, D. (1999). Prochlorococcus, a marine photosynthetic prokaryote of global significance. Microbiol. Mol. Biol. Rev. 63, 106-127.

Pluskal, T., Castillo, S., Villar-Briones, A., and Orešič, M. (2010). MZmine 2: modular framework for processing, visualizing, and analyzing mass spectrometry-based molecular profile data. BMC Bioinformatics 11:395. doi: 10.1186/1471-2105-11-395

Pomeroy, L. R. (1974). The ocean's food web, a changing paradigm. Bioscience 24, 499-504. doi: 10.2307/1296885

Poretsky, R. S., Sun, S., Mou, X., and Moran, M. A. (2010). Transporter genes expressed by coastal bacterioplankton in response to dissolved organic carbon. Environ. Microbiol. 12, 616-627. doi: 10.1111/j.1462-2920.2009. 02102.x

Rocap, G., Distel, D. L., Waterbury, J. B., and Chisholm, S. W. (2002). Resolution of Prochlorococcus and Synechococcus ecotypes by using 16S-23S ribosomal DNA internal transcribed spacer sequences. Appl. Environ. Microbiol. 68, 1180-1191. doi: 10.1128/AEM.68.3.1180-1191.2002

Rocap, G., Larimer, F. W., Lamerdin, J., Malfatti, S., Chain, P., Ahlgren, N. A., et al. (2003). Genome divergence in two Prochlorococcus ecotypes reflects oceanic niche differentiation. Nature 424, 1042-1047. doi: 10.1038/nature01947

Romera-Castillo, C., Sarmento, H., Alvarez-Salgado, X. A., Gasol, J. M., and Marrase, C. (2010). Production of chromophoric dissolved organic matter by marine phytoplankton. Limnol. Oceanogr. 55, 446-454. doi: 10.4319/lo.2010.55.1.0446

Romera-Castillo, C., Sarmento, H., Alvarez-Salgado, X. A., Gasol, J. M., and Marrase, C. (2011). Net production and consumption of fluorescent colored dissolved organic matter by natural bacterial assemblages growing on marine phytoplankton exudates. Appl. Environ. Microbiol. 77, 7490-7498. doi: 10.1128/AEM.00200-11

Rubio, L. M., Flores, E., and Herrero, A. (1999). Molybdopterin guanine dinucleotide cofactor in Synechococcus sp. nitrate reductase: identification of
mobA and islation of a putative moeB gene. FEBS Lett. 462, 358-362. doi: 10.1016/S0014-5793(99)01556-2

Sarmento, H., and Gasol, J. M. (2012). Use of phytoplankton-derived dissolved organic carbon by different types of bacterioplankton. Environ. Microbiol. 14, 2348-2360. doi: 10.1111/j.1462-2920.2012.02787.x

Schwarz, D., Orf, I., Kopka, J., and Hagemann, M. (2013). Recent applications of metabolomics toward cyanobacteria. Metabolites 3, 72-100. doi: 10.3390/metabo3010072

Sharma, A. K., Becker, J. W., Ottesen, E. A., Bryant, J. A., Duhamel, S., Karl, D. M., et al. (2013). Distinct dissolved organic matter sources induce rapid transcriptional responses in co-existing populations of Prochlorococcus, Pelagibacter and the OM60 Clade. Environ. Microbiol. doi: 10.1111/1462-2920.12254. [Epub ahead of print].

Sorhannus, U. (2004). Diatom phylogenetics inferred based on direct optimization of nuclear-encoded SSU rRNA sequences. Cladistics 20, 487-497. doi: 10.1111/j.1096-0031.2004.00034.x

Soule, M. C. K., Longnecker, K., Giovannoni, S. J., and Kujawinski, E. B. (2010). Impact of instrument and experiment parameters on reproducibility of ultrahigh resolution ESI FT-ICR mass spectra of natural organic matter. Org. Geochem. 41, 725-733. doi: 10.1016/j.orggeochem.2010.05.017

Tautenhahn, R., Cho, K., Uritboonthai, W., Zhu, Z., Patti, G. J., and Siuzdak, G. (2012a). An accelerated workflow for untargeted metabolomics using the METLIN database. Nat. Biotechnol. 30, 826-828. doi: 10.1038/nbt.2348

Tautenhahn, R., Patti, G. J., Rinehart, D., and Siuzdak, G. (2012b). XCMS Online: a web-based platform to process untargeted metabolomic data. Anal. Chem. 84, 5035-5039. doi: 10.1021/ac300698c

Waterbury, J., Watson, S. W., Valois, F. W., and Franks, D. G. (1986). Biological and ecological characterization of the marine unicellular bacterium Synechococcus. Can. Bull. Fish. Aquat. Sci. 214, 71-120.

Wetz, M. S., and Wheeler, P. A. (2007). Release of dissolved organic matter by coastal diatoms. Limnol. Oceanogr. 52, 798-807. doi: 10.4319/lo.2007.52.2.0798

Conflict of Interest Statement: The authors declare that the research was conducted in the absence of any commercial or financial relationships that could be construed as a potential conflict of interest.

Received: 26 July 2013; accepted: 05 March 2014; published online: 28 March 2014. Citation: Becker JW, Berube PM, Follett CL, Waterbury JB, Chisholm SW, DeLong EF and Repeta DJ (2014) Closely related phytoplankton species produce similar suites of dissolved organic matter. Front. Microbiol. 5:111. doi: 10.3389/fmicb.2014.00111 This article was submitted to Microbiological Chemistry, a section of the journal Frontiers in Microbiology.

Copyright (c) 2014 Becker, Berube, Follett, Waterbury, Chisholm, DeLong and Repeta. This is an open-access article distributed under the terms of the Creative Commons Attribution License (CC BY). The use, distribution or reproduction in other forums is permitted, provided the original author(s) or licensor are credited and that the original publication in this journal is cited, in accordance with accepted academic practice. No use, distribution or reproduction is permitted which does not comply with these terms. 